Archives de sciences sociales des religions

134 | avril - juin 2006

Varia

\title{
Helmut Thielen, Eingedenken und Erlösung. Walter
}

Benjamin

Würzburg, Königshausen \& Neumann, 2005, 377 p.

Michael Löwy

\section{OpenEdition}

\section{Journals}

Édition électronique

URL : http://journals.openedition.org/assr/3634

DOI : 10.4000/assr.3634

ISSN : $1777-5825$

Éditeur

Éditions de l'EHESS

Édition imprimée

Date de publication : 1 mai 2006

Pagination : 147-299

ISBN : 2-7132-2092-0

ISSN : 0335-5985

Référence électronique

Michael Löwy, «Helmut Thielen, Eingedenken und Erlösung. Walter Benjamin », Archives de sciences sociales des religions [En ligne], 134 | avril - juin 2006, document 134-84, mis en ligne le 12 septembre 2006, consulté le 21 septembre 2020. URL : http://journals.openedition.org/assr/3634 ; DOI : https:// doi.org/10.4000/assr.3634

Ce document a été généré automatiquement le 21 septembre 2020

(c) Archives de sciences sociales des religions 


\section{Helmut Thielen, Eingedenken und Erlösung. Walter Benjamin}

Würzburg, Königshausen \& Neumann, 2005, 377 p.

\section{Michael Löwy}

1 Il s'agit, ici, d'un ouvrage interdisciplinaire, associant philosophie, théologie et science sociale, d'une érudition impressionnante. L'auteur, universitaire allemand (ancien élève de l'École de Francfort) établi au Brésil depuis 1994, ne cache pas son engagement religieux (chrétien) et social, et sa lecture de l'œuvre de Walter Benjamin est originale, polémique et stimulante. Rejetant les lectures modernes (Habermas) ou post-modernes du penseur juif/allemand, il le situe dans le contexte de la Théorie critique (Adorno, Horkheimer) et de son programme d'émancipation humaine. Malgré de nombreuses digressions - sur la dimension théologique chez Adorno, sur les rapports entre théocratie et anarchie dans la pensée juive, sur les différentes formes de sécularisation du messianisme - le fil rouge de l'œuvre est aisément perceptible : la dialectique entre théologie et praxis émancipatrice dans la pensée de Benjamin. Une dialectique qui trouve, comme le montre très bien $\mathrm{H}$. Thielen, un équivalent, non identique, dans la théologie de la libération en Amérique Latine.

2 Deux textes de jeunesse de Benjamin, de 1921-22, occupent une place importante dans le livre : le Fragment théologico-politique, où il tente, sans y réussir tout à fait, de mettre en rapport la dimension « horizontale », profane, de la recherche humaine du bonheur, avec la " verticale », messianique, de la rédemption; et le fragment Le capitalisme comme religion, qui, en radicalisant la thèse de Max Weber, décrit le capitalisme non seulement comme le produit de causes religieuses (l'éthique protestante), mais comme, substantiellement, une religion, un culte impitoyable, qui requiert des sacrifices et engendre le désespoir.

3 Cependant, l'argument du livre tourne essentiellement autour de deux affirmations de Walter Benjamin sur les liens entre le théologique et le politique: d'une part, un fragment du Livre des Passages Parisiens: "Ma pensée se comporte envers la théologie comme le buvard envers l'encre. Elle en est complètement imbibée. Mais s'il en allait selon le buvard, rien de ce qui est écrit ne subsisterait »; d'autre part, la célèbre Thèse I 
Sur le concept d'histoire (1940), où un nain théologique, " petit et laid» (mais maître en échecs) se cache à l'intérieur d'un automate joueur d'échecs, dénommé «matérialisme historique ", et lui permet de gagner toutes les parties.

4 Selon l'auteur, la démarche de Benjamin est celle d'une intégrale profanation de la théologie dans la praxis/théorie émancipatrice. H. Thielen utilise le terme Profanierung, emprunté à Adorno, non dans le sens qu'il a en français, "violation du sacré », mais comme une sorte d'équivalent de sécularisation, sans qu'on sache exactement les motifs de cette substitution terminologique. L'allégorie du buvard signifierait donc que la théologie - c'est-à-dire certaines traditions juives, autour du prophétisme et du messianisme - disparaît entièrement, sans reste, absorbée par le matérialisme historique. L'«illumination profane » dont se réclame Benjamin consisterait ainsi dans la transformation matérialiste d'une expérience religieuse en profane. Dans l'allégorie de l'automate joueur d'échecs, la théologie doit rendre sa vitalité messianique au matérialisme historique - transformé en marionnette morte par les idéologues du marxisme officiel - mais elle finit par disparaitre tout à fait dans les luttes émancipatrices. La dialectique entre théologie et marxisme chez Benjamin est asymétrique, parce que, pour sauver le second, la première doit se sacrifier et s'autosupprimer. Cette "profanation » intégrale de la théologie dans des pratiques purement séculaires empêche Benjamin, selon $\mathrm{H}$. Thielen, de se dissocier des aspects les plus problématiques de ces dernières (la violence notamment).

5 L'auteur aboutit donc à une critique de Benjamin, au nom d'un autre paradigme de "profanation" de la théologie, où celle-ci se maintiendrait, dans une tension permanente avec les luttes émancipatrices. Dans cette variante, la distance entre la transcendance - l'amour divin - et le monde profane est maintenue : les deux pôles entrent dans un rapport de médiation dialectique, mais restent distincts et autonomes. Cette dialectique trouve son expression dans l'œuvre de socialistes religieux comme Martin Buber ou le pasteur suisse Leonhard Ragaz, et dans les pratiques émancipatrices non-violentes (Gandhi, Martin Luther King).

Qu'on partage ou non les conclusions de l'auteur, l'ouvrage est fort intéressant: il contient non seulement une passionnante exégèse de Walter Benjamin, mais aussi un bel hommage à l'actualité des énigmatiques questions politico-théologiques qu'il pose. 